\title{
Optimum ratio of standardized ileal digestible tryptophan to lysine for piglets
}

KEY WORDS: lysine, tryptophan, requirement, piglet

Received: 10 April 2013

Revised: 24 October 2013

Accepted: 28 October 2013

${ }^{1}$ Corresponding author:

martin_nyachoti@umanitoba.ca

\begin{abstract}
Two experiments were conducted to determine optimal standardized ileal digestible (SID) tryptophan:lysine ratio for piglets using growth performance and plasma urea $\mathrm{N}$ as response criteria. In Experiment 1, piglets were fed 6 diets with $8.5,9.5,10.5,11.5,12.5$ or $13.5 \mathrm{~g} \cdot \mathrm{kg}^{-1}$ SID lysine to estimate lysine requirement. In Experiment 2, piglets were fed 6 diets with $9.2 \mathrm{~g} \cdot \mathrm{kg}^{-1}$ SID lysine, and $0.178,0.182,0.196,0.216,0.227$ or $0.236 \mathrm{SID}$ trytophan:lysine to estimate optimal tryptophan:lysine ratio. The SID lysine requirement was estimated to be $10.2 \mathrm{~g} \cdot \mathrm{kg}^{-1}$. Response criteria measured were unaffected by SID tryptophan:lysine ratio, implying that the diets fed were not deficient in tryptophan. In conclusion, the SID lysine requirement for the piglets was close to the recommendation by NRC $\left(1998 ; 10.1 \mathrm{~g} \cdot \mathrm{kg}^{-1}\right)$, but not NRC $\left(2012 ; 12.3 \mathrm{~g} \cdot \mathrm{kg}^{-1}\right)$. The optimal SID tryptophan:lysine ratio of the piglets was either equal to or less than 0.178 .
\end{abstract}

\section{Introduction}

Tryptophan (Trp) is the second or the third limiting amino acid (AA) in practical pig diets depending on diet type (Guzik et al., 2005). Thus, for improved performance, there is a need to supply pigs with the required amount of digestible Trp. The dietary requirements of most AA are often expressed as a ratio to the requirement for lysine (Lys), which is the first limiting AA in practical pig diets (Boisen et al., 2000). Thus, digestible Trp requirement should be expressed as a ratio to digestible Lys.

Dietary Trp requirements for pigs have been investigated (Susenbeth and Lucanus, 2005). However, there is still limited and variable information on the optimal standardized ileal digestible (SID) Trp:Lys ratio for piglets. For example, Guzik et al. (2002) reported an optimal SID Trp:Lys as 0.178 for
10 to $16 \mathrm{~kg}$ piglets, whereas Jansman et al. (2010) reported the optimal SID Trp:Lys as 0.210 for $8 \mathrm{~kg}$ piglets. When determining the optimal ratio of SID content of an AA to SID Lys, the level of SID Lys should be kept at $90 \%$ or $95 \%$ of its optimal requirement to ensure validity of the results (Van Cauwenberghe and Relandeau, 2000). However, the optimal requirement of SID Lys by piglets has been variable, and the variation has been attributed to many factors including pig genotype and method used for the estimation of Lys requirement (Kendall et al., 2008). Thus, in order to determine the optimal SID Trp:Lys for piglets, there is a need to know first the requirement of Lys for the piglets. However, there is limited information on the optimal SID Trp:Lys for piglets fed a diet with SID Lys at slightly below the requirement. Among the statistical methods used to determine the AA requirement, the broken-line 
analysis is preferred (Robbins et al., 2006). The objective of this study was first to determine the SID Lys requirement of piglets and then to use a diet with $90 \%$ of the Lys requirement to determine the optimal SID Trp:Lys ratio for the piglets using the broken-line analysis method.

\section{Material and methods}

All experimental procedures were reviewed and approved by the University of Manitoba Animal Care Protocol Management and Review Committee, and pigs were handled in accordance with the guidelines described by the Canadian Council on Animal Care (CCAC, 2009). The pigs used in both experiments were Yorkshire $\times$ Landrace barrows and gilts obtained from Iceman Genetics (St. Eustache, Manitoba, Canada).

\section{Experiment 1}

The experiment was conducted to estimate the Lys requirement of weaned pigs using growth performance and plasma urea N (PUN) as the response criteria. Seventy-two piglets (balanced for sex) with an initial body weight (BW) of $8.73 \pm$ $1.13 \mathrm{~kg}$ (mean $\pm \mathrm{SD}$ ) were obtained immediately after weaning, and group-housed in pens ( 8 pigs per pen). The piglets were then monitored for consumption of a commercial starter diet for 4 days to ensure that they were healthy piglets that were able to eat. After 4 days, piglets were divided into 24 groups of 3 piglets (of the same sex) balanced for BW. Each group was then housed in a pen $(1.5 \times 1.2 \mathrm{~m})$ with smooth sides and plastic covered expanded metal flooring in a temperature-controlled room $\left(30 \pm 2^{\circ} \mathrm{C}\right)$ and fed the experimental diets.

Six experimental diets fed were formulated to contain $8.5,9.5,10.5,11.5,12.5$ or $13.5 \mathrm{~g} \cdot \mathrm{kg}^{-1}$ SID Lys (Table 1) using previously analysed AA values of feed ingredients and SID coefficients obtained from Rademacher et al. (2000). The AA contents in wheat, soyabean meal and barley were analysed using near-infrared spectroscopy (NIRS) as described by Fontaine et al. $(2002,2004)$ because of availability of robust prediction models for these feed ingredients. The AA contents in field pea, maize gluten feed, spray dried blood plasma and dried whey were determined by wet chemistry following the guidelines of Commission Directive (1998, 2000) at Degussa AG (Hanau-Wolfgang, Germany) because the NIR procedure was deemed unsuitable for these ingredients due to lack of robust predic-

Table 1. Composition of experimental diets used in Experiments 1 and 2, as-fed basis

\begin{tabular}{|c|c|c|c|c|c|c|c|c|c|c|c|c|}
\hline \multirow{2}{*}{ Indices } & \multicolumn{6}{|c|}{ SID lysine, $\mathrm{g} \cdot \mathrm{kg}^{-1}$} & \multicolumn{6}{|c|}{ SID trptophan:lysine } \\
\hline & 8.5 & 9.5 & 10.5 & 11.5 & 12.5 & 13.5 & 0.178 & 0.182 & 0.196 & 0.216 & 0.227 & 0.236 \\
\hline \multicolumn{13}{|l|}{ Ingredient, $\mathrm{g} \cdot \mathrm{kg}^{-1}$} \\
\hline barley & 190.9 & 190.9 & 190.9 & 190.9 & 190.9 & 190.9 & 180.9 & 180.9 & 180.9 & 180.9 & 180.9 & 180.9 \\
\hline wheat & 125.0 & 125.0 & 125.0 & 125.0 & 125.0 & 125.0 & 112.5 & 112.5 & 112.5 & 112.5 & 112.5 & 112.5 \\
\hline soyabean meal & 40.0 & 40.0 & 40.0 & 40.0 & 40.0 & 40.0 & 14.0 & 14.0 & 14.0 & 14.0 & 14.0 & 14.0 \\
\hline maize gluten feed & 319.6 & 317.7 & 314.3 & 312.8 & 311.3 & 309.9 & 372 & 371.9 & 371.8 & 371.5 & 371.4 & 371.2 \\
\hline field pea & 131.8 & 131.8 & 131.8 & 131.8 & 131.8 & 131.8 & 132.7 & 132.7 & 132.7 & 132.7 & 132.7 & 132.7 \\
\hline d plasma & 48.0 & 48.0 & 48.0 & 48.0 & 48.0 & 48.0 & 40.0 & 40.0 & 40.0 & 40.0 & 40.0 & 40.0 \\
\hline dried & 65.0 & 65.0 & 65.0 & 65.0 & 65.0 & 65.0 & 65.0 & 65.0 & 65.0 & 65.0 & 65.0 & 65.0 \\
\hline cano & 50.0 & 50.0 & 50.0 & 50.0 & 50.0 & 50.0 & 50.0 & 50.0 & 50.0 & 50.0 & 50.0 & 50.0 \\
\hline limestone & 10.8 & 10.7 & 10.6 & 10.6 & 10.6 & 10.6 & 10.8 & 10.8 & 10.8 & 10.8 & 10.8 & 10.8 \\
\hline mono & 5.00 & 5.10 & 5.20 & 5.30 & 5.40 & 5.40 & 5.0 & 5.0 & 5.0 & 5.0 & 5.0 & 5.0 \\
\hline Premix ${ }^{1}$ & 10.0 & 10.0 & 10.0 & 10.0 & 10.0 & 10.0 & 10.0 & 10.0 & 10.0 & 10.0 & 10.0 & 10.0 \\
\hline L-lys & - & 1.90 & 5.10 & 6.50 & 7.90 & 9.30 & 2.50 & 2.50 & 2.50 & 2.60 & 2.60 & 2.60 \\
\hline DL-m & 1.80 & 1.80 & 1.80 & 1.80 & 1.80 & 180 & 2.00 & 2.00 & 2.00 & 2.00 & 2.00 & 2.00 \\
\hline L-thre & - & - & 0.10 & 0.10 & & & - & - & - & - & - & - \\
\hline L-tryp & 0.40 & 0.40 & 0.40 & 0.40 & 0.40 & 0.4 & - & 0.10 & 0.20 & 0.40 & 0.50 & 0.70 \\
\hline L-isole & 1.30 & 1.30 & 1.30 & 1.30 & 1.30 & 1.30 & 1.70 & 1.70 & 1.70 & 1.70 & 1.70 & 1.70 \\
\hline L-valir & 0.40 & 0.40 & 0.50 & 0.50 & 0.50 & 0.50 & 0.90 & 0.90 & 0.90 & 0.90 & 0.90 & 0.90 \\
\hline Calculated $\mathrm{ME}^{2}, \mathrm{MJ} \cdot \mathrm{kg}^{-1}$ & 13.1 & 13.0 & 13.0 & 13.0 & 13.0 & 13.0 & 12.9 & 12.9 & 12.9 & 12.9 & 12.9 & 12.9 \\
\hline Calculated crude protein, $\mathrm{g} \cdot \mathrm{kg}^{-1}$ & 200 & 202 & 204 & 205 & 206 & 207 & 194 & 194 & 194 & 194 & 194 & 195 \\
\hline Analysed crude protein, $\mathrm{g} \cdot \mathrm{kg}^{-1}$ & 209 & 208 & 212 & 206 & 207 & 208 & 200 & 197 & 191 & 199 & 200 & 201 \\
\hline Analysed lysine, $\mathrm{g} \cdot \mathrm{kg}^{-1}$ & 10.8 & 11.7 & 13.9 & 14.6 & 15.3 & 15.2 & 11.3 & 11.2 & 11.0 & 11.1 & 11.1 & 11.3 \\
\hline Analysed tryptophan, $\mathrm{g} \cdot \mathrm{kg}^{-1}$ & 2.70 & 2.60 & 2.70 & 2.70 & 2.80 & 2.70 & 2.10 & 2.10 & 2.20 & 2.40 & 2.50 & 2.60 \\
\hline
\end{tabular}

SID - standardized ileal digestible; ME - metabolizable energy; ${ }^{1}$ Premix supplied per $\mathrm{kg}$ of diet: IU: vit. A 8255, vit. $\mathrm{D}_{3} 1000$, vit. E 20; mg: vit. K 1.5, riboflavin 7.5, niacin 30, pyridoxine 4.5, folic acid 1, thiamin 4, choline 781, Cu 10, I 0.6, Fe 130, Mg 40, Se 0.3, Zn 130; $\mu$ g: vit. $B_{12} 25$, biotin 200. ${ }^{2}$ the feed ingredient ME value data used in the diet formulations were obtained from NRC (1998) 
tion models. Diets were formulated to differ only in their Lys content. All other nutrients were supplied in amounts meeting or exceeding NRC (1998) recommendations.

The 6 diets were randomly assigned to the groups (4 groups per diet; 2 groups of each gender per diet) for 15 days. Pigs were allowed ad libitum access to feed and water. Feed intake and BW were monitored every 5 days for the determination of average daily gain (ADG), average daily feed intake (ADFI) and gain:feed (G:F) ratio. Also, blood samples $(10 \mathrm{ml})$ were obtained from one pig per pen every 5 days via jugular vein puncture into vacutainer tubes coated with sodium heparin (Becton Dickinson, Rutherford, NJ). The samples were immediately centrifuged at $2000 \mathrm{~g}$ for $10 \mathrm{~min}$. at $4{ }^{\circ} \mathrm{C}$ to recover plasma, which was stored at $-20^{\circ} \mathrm{C}$ until analysed for plasma urea N (PUN).

\section{Experiment 2}

The experiment was conducted to estimate the optimal Trp:Lys for weaned pigs using growth performance and PUN as the response criteria. Seventy-two weaned piglets (balanced for sex) with an initial BW of $7.88 \pm 0.63 \mathrm{~kg}$ (mean \pm SD) were housed and fed for 4 days as described in Experiment 1 . On day 5, the piglets were divided into 36 groups of 2 piglets balanced for BW and sex, and each group was housed in a pen within a room as described in Experiment 1.

Six experimental diets contained $9.2 \mathrm{~g} \cdot \mathrm{kg}^{-1}$ SID Lys and 1.64, 1.67, 1.80, 2.00, 2.09 or $2.17 \mathrm{~g} \cdot \mathrm{kg}^{-1}$ SID Trp, and hence 0.178, 0.182, $0.196,0.216,0.227$ or 0.236 SID Trp:Lys (Table 1) based on the analysed AA values of feed ingredients (from Experiment 1) and the SID coefficients from Rademacher et al. (2000). Diets were formulated to differ only in their SID Trp content. All other nutrients were supplied in amounts meeting or exceeding NRC (1998) recommendations except for SID Lys, which was set at $90 \%$ of the optimal requirement value determined in Experiment 1. The 6 diets were randomly assigned to 6 groups each, and fed for 3 weeks. During this period, pigs were allowed ad $l i-$ bitum access to feed and water. Feed intake and BW were monitored weekly to determine ADG, ADFI and G:F. Blood was sampled $(10 \mathrm{ml})$ weekly from one pig per pen for analysis of PUN.

\section{Sample preparation and analyses}

Samples of diets were ground to pass through a 1-mm screen using a Willey mill (Arthur $\mathrm{H}$. Thomas, Philadelphia, PA), and thoroughly mixed for analysis. Diet samples were analysed for $\mathrm{N}$ con- tent using a N analyzer (Model CNS-2000, Leco Corporation, St. Joseph, MI). Feedstuffs and diets were analysed for AA by wet chemistry method according to AOAC (2006; method 988.15 for Trp and 982.30 for the other AA). Plasma samples were thawed and then analysed for PUN using a Nova Stat Profile M Blood Gas and Electrolyte Analyzer (Nova Biomedical Corporation, Waltham, MA).

\section{Statistical analysis}

Data were analysed as a completely randomized design using general linear model procedure (SAS Inst. Inc., Cary, NC). Linear and quadratic contrasts for unequally spaced levels were performed to assess the effect of increasing dietary level of SID Lys (Experiment 1) or SID Trp:Lys (Experiment 2). To determine the optimal SID Lys (Experiment 1) or SID Trp:Lys (Experiment 2) levels, the data were subjected to a broken-line analysis (Robbins et al., 2006) using the Proc NLIN of SAS (SAS Inst. Inc. Cary, NC).

\section{Results}

\section{Experiment 1}

The analysed dietary crude protein values were similar to calculated values in Table 1 . There was no effect $(P>0.10)$ of dietary Lys content on ADG (Table 2). However, ADFI tended to decline linearly $(P=0.070)$ as dietary SID Lys content increased (Table 2). This resulted in a tendency towards a linear increase $(P=0.081)$ in $\mathrm{G}: \mathrm{F}$ with increasing dietary Lys content. There was a linear $(P=$ 0.03) decrease in PUN content on day 15 of the experiment due to increasing dietary Lys content (Table 2). Using G:F as a response criterion, the optimal SID Lys requirement was determined to be $10.3 \pm 0.6 \mathrm{~g} \cdot \mathrm{kg}^{-1}\left(P=0.01 ; \mathrm{R}^{2}=0.36\right.$; Figure 1$) ;$ whereas the value obtained when using pooled PUN content was $10.1 \pm 0.4 \mathrm{~g} \cdot \mathrm{kg}^{-1}\left(P=0.01 ; \mathrm{R}^{2}=0.41\right.$; Figure 2).

Averaging the values obtained with the two response criteria, the SID Lys requirement was determined to be $10.2 \pm 0.1 \mathrm{~g} \cdot \mathrm{kg}^{-1}$.

\section{Experiment 2}

The analysed dietary crude protein values were similar to the calculated values in Table 1 . There were no effects $(P>0.10)$ of dietary SID Trp:Lys on ADG, ADFI, G:F and PUN (Table 2). Also, none of the response criteria measured in the current experiment yielded an optimal dietary SID Trp:Lys estimate. 
Table 2. Performance and plasma urea nitrogen (PUN) of piglets fed diets with six levels of standardized ileal digestible (SID) lysine (Experiment 1); and performance and PUN of piglets fed diets with six levels of SID tryptophan:lysine (Trp:Lys; Experiment 2)

\begin{tabular}{|c|c|c|c|c|c|c|c|c|c|c|c|c|c|c|c|c|c|c|}
\hline \multirow{2}{*}{ Indices } & \multicolumn{6}{|c|}{ SID lysine, $\mathrm{g} \cdot \mathrm{kg}^{-1}$} & \multirow{2}{*}{ EM } & \multicolumn{2}{|c|}{$P$-values ${ }^{1}$} & \multicolumn{6}{|c|}{ SID trptophan:lysine } & \multirow{2}{*}{ SEM } & \multicolumn{2}{|c|}{$P$-values } \\
\hline & 8.5 & 9.5 & 10.5 & 11.5 & 12.5 & 3.5 & & Lin & Quad & 0.178 & 0.182 & 0.196 & 0.216 & .227 & .236 & & Lin & Qua \\
\hline & 84 & , & 46 & 80 & 8.71 & 72 & & 0.64 & & 86 & & & & 5 & & 0.26 & & \\
\hline & 1 & 13 & 13.5 & 13.8 & 13.3 & 8 & 0.4 & 0.40 & 0. & 3.8 & & & 14.7 & 13 & & 83 & 0 & 0.92 \\
\hline & 7 & 545 & 546 & 50 & 510 & 5 & & 0.07 & 0. & 8 & & & & 40 & & & 0.6 & \\
\hline & & 326 & 341 & 333 & 309 & 34 & & 0.50 & 0.7 & 282 & & & 30 & 26 & & & 0. & 0.99 \\
\hline 1 & 57 & 60 & 0.62 & 61 & 0.61 & 0.62 & 2 & 0.08 & 0.2 & 0.62 & 22 & 62 & 0.60 & 0.64 & 0. & .02 & 0.73 & 077 \\
\hline & 90 & 4.4 & 15 & 4.30 & 4.9 & & & 0.83 & & & & & & & & 26 & & \\
\hline & 5.18 & 3.85 & 3.20 & 4.13 & 3.50 & 3.3 & 49 & 0.03 & 0.1 & 4.00 & & & 3.68 & 3.85 & & .20 & 0.37 & 0.85 \\
\hline ean value & 5.28 & 3.89 & 3.19 & 3.70 & 3.59 & 3.45 & .47 & 0.01 & 0.08 & 3.97 & 4.36 & 3.96 & 3.86 & 3.87 & 4.00 & 0.19 & 0.24 & 0.49 \\
\hline
\end{tabular}

${ }^{1} \mathrm{Lin}$ - linear; Quad - quadratic; ${ }^{2}$ Baseline value - PUN value at the beginning of the experiment; final value - PUN value at the end of the experiment; mean value - average of the PUN values for days 5, 10 and 15 of the Experiment 1, and days 7, 14 and 21 of Experiment 2; BW - body weight; $A D F I$ - average daily feed intake; ADG - average daily gain

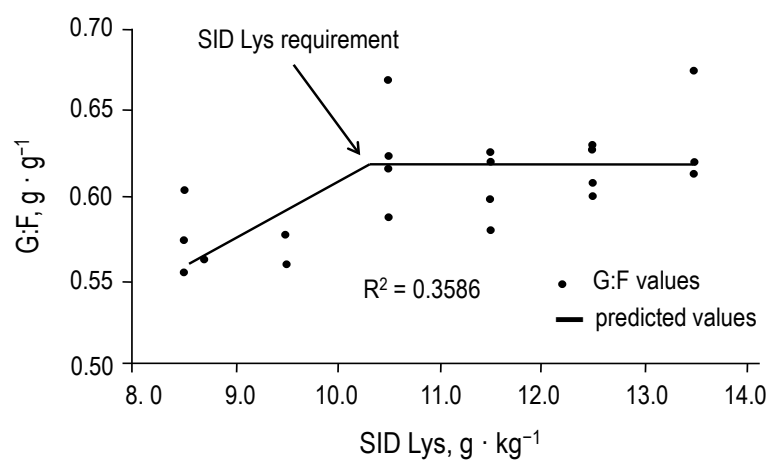

Figure 1. Determination of standardized ileal digestible (SID) Lys requirement of piglets fed diets with six levels of SID lysine in Experiment 1 using the broken-line analysis and gain:feed ratio as a response criteria. Equation line: Pred. $G: F=L+U$ * (Z1) where: Pred G:F - predicted value of G:F; $L$ - asymptote $=0.618$ $\pm 0.007 ; \mathrm{U}$ - slope $=-0.388 \pm 0.223 ;$ and $\mathrm{Z1}-(\mathrm{X}<\mathrm{SID}$ Lys $)$ ${ }^{*}$ (requirement - SID Lys). Standardized ileal digestible Lys requirement $=1.03 \pm 0.062(P=0.01)$

\section{Discussion}

The ADFI values observed in Experiments 1 and 2 were similar to values reported by other studies (530 g, Burgoon et al., 1992; 559 g, Eder et al., 2001) for 6 to $16 \mathrm{~kg}$ pigs. The ADFI (Experiment 1) decreased with an increase in dietary SID Lys content, resulting in a tendency towards an increase in G:F due to an increase in dietary SID Lys content. Smith et al. (1999) also reported a decrease in ADFI and an increase in G:F of 10 to $25 \mathrm{~kg}$ pigs due to an increase in dietary SID Lys content. In their study, they had increased dietary SID Lys content by increasing the inclusion level of soyabean meal in the basal diet. However, Yi et al. (2006) did not observe reduced ADFI by 12 to $24 \mathrm{~kg}$ pigs due to increased dietary SID Lys content achieved through increasing the inclusion level of crystalline Lys in the basal diet. Kendall et al. (2008) attributed

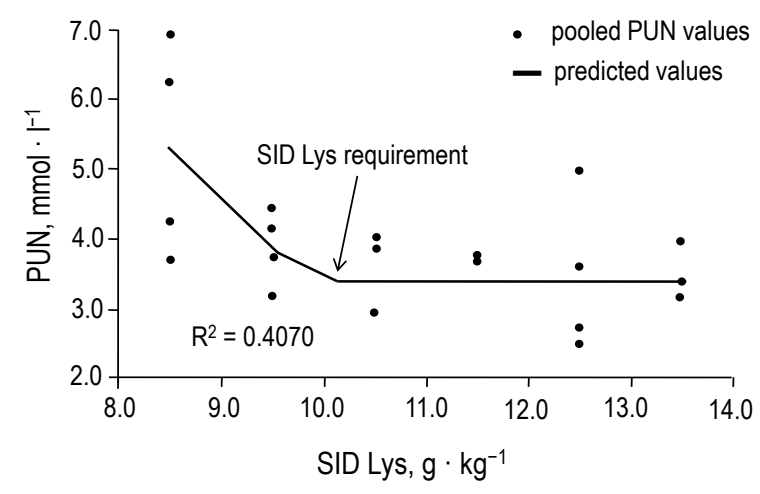

Figure 2. Determination of standardized ileal digestible (SID) Lys requirement of piglets fed diets with six levels of SID lysine in Experiment 1 using the broken-line analysis and pooled plasma urea nitrogen (PUN) as a response criteria. Equation line: Pred. PUN $=L+$ $U^{*}$ (Z1) where: Pred. PUN - predicted value of PUN; L - asymptote $-3.457 \pm 0.225$; U - slope - $15.417 \pm 6.855$; and Z1 - (SID Lys < requirement) * (requirement - SID Lys). Standardized ileal digestible Lys requirement $=1.01 \pm 0.041(P<0.01)$

the reduced ADFI of pigs by dietary SID Lys in studies in which dietary SID Lys increased through increasing protein-rich feed ingredients such as soyabean meal to increased deamination of surplus protein in diets with high Lys content. However, in the current study, dietary SID Lys was increased by increasing the dietary level of crystalline Lys. Thus, it is still unclear why dietary SID Lys would reduce ADFI in some studies but not in others.

Plasma urea $\mathrm{N}$ concentration in pigs is inversely related to dietary level of the first limiting AA. This is because an increase in AA utilization by pigs due to an increase in dietary level of the first limiting AA results in a decrease in PUN concentration (Coma et al., 1995). Thus, PUN can be used to accurately determine the Lys requirement in pigs (Coma et al., 1995). In Experiment 1 of the current study, the average PUN content was decreased as the dietary SID Lys content increased. These results are 
in agreement with those of Nam and Aherne (1994) and Dean et al. (2007), who reported a linear decrease in PUN content in nursery pigs with BW ranges of 9 to $25 \mathrm{~kg}$, and 6 to $12 \mathrm{~kg}$ due to an increase in dietary total Lys and SID Lys contents, respectively.

The optimal SID Lys requirement estimated by the broken-line analysis of G:F $\left(10.3 \mathrm{~g} \cdot \mathrm{kg}^{-1}\right)$ was similar to the value estimated by the analysis of average PUN (10.1 $\left.\mathrm{g} \cdot \mathrm{kg}^{-1}\right)$. Growth performance compared with PUN was shown to produce lower estimates of Lys requirement, which was attributed to the fact that AA requirement for maximum protein accretion, which is reflected by PUN, is higher than the requirement for maximum growth (Coma et al., 1995). However, this was not the case in the current study, implying that growth performance and PUN can produce similar estimates of SID Lys requirement by pigs.

The estimated SID Lys requirement of piglets in the current study is close to the NRC (1998) recommendations for the 10 to $20 \mathrm{~kg}$ pigs $\left(10.1 \mathrm{~g} \cdot \mathrm{kg}^{-1}\right)$, but lower than the NRC (2012) recommendations for pigs in the same BW range $\left(12.3 \mathrm{~g} \cdot \mathrm{kg}^{-1}\right)$. Also, the value is lower than the SID Lys requirement values reported by Yi et al. (2006; $\left.13.2 \mathrm{~g} \cdot \mathrm{kg}^{-1}\right)$ and Kendall et al. $\left(2008 ; 13.0 \mathrm{~g} \cdot \mathrm{kg}^{-1}\right)$ for 12 to $24 \mathrm{~kg}$ piglets, and 11 to $27 \mathrm{~kg}$ piglets, respectively. The SID Lys requirement of pigs varies partly with genotype because different genotypes have different rates of protein accretion (Dean et al., 2007). Therefore, the differences in the estimates of SID Lys requirement of pigs among studies could be due to differences in genotypes of pigs used in the different studies.

The purpose of Experiment 2 was to determine the optimal dietary SID Trp:Lys of piglets. The SID Lys level selected $\left(9.2 \mathrm{~g} \cdot \mathrm{kg}^{-1}\right)$ was set to be $10 \%$ lower than the requirement level that was established in Experiment 1. Setting the SID Lys requirement to this level was done to maximize the utilization of Lys (first limiting AA) and Trp (second limiting AA for this study) by the piglets (Van Cauwenberghe and Relandeau, 2000).

There was no effect of dietary SID Trp:Lys on any of the response criterion measured in Experiment 2. Also, optimal dietary SID Trp:Lys was not achieved by any of the response criteria measured in the same experiment. This is contrary to the results from the studies of Burgoon et al. (1992), Eder et al. (2001) and Guzik et al. (2002) who reported increased growth performance of 6 to $16 \mathrm{~kg}, 7.5$ to $24 \mathrm{~kg}$ and 10 to $16 \mathrm{~kg}$ pigs due to an increase in apparent ileal digestible, apparent ileal digestible and SID Trp:Lys in Trp-deficient diets, respectively. However, it should be noted that the Trp values for feed ingredients (barley, wheat and soyabean meal) that were used to formulate diets used in this experiment had been determined using near-infrared spectroscopy at Degussa AG (Hanau-Wolfgang, Germany). Wu et al. (2002) failed to quantify the amount of Trp in rice samples using near infra-red spectroscopy due to its low concentration, indicating that the wet chemistry method is better for determination Trp content in cereals than the near infra-red spectroscopy. Fontaine et al. (2002, 2004) observed a higher coefficient of variation and coefficient of determination for Trp than for the other AA when near infra-red spectroscopy method was used for predicting AA content of feedstuff. Also, it is not unusual to find variations on AA evaluation among laboratories even when the same method of analysis is used (Cromwell et al., 1999), and those differences are greater when analysing Trp (Sato et al., 1984). Therefore, the lack of effect of dietary SID Trp:Lys in the current study could have been due to laboratory underestimation of the total Trp content in the feed ingredient samples used to formulate the basal diet that was fed to the piglets. The dietary SID Trp:Lys had been anticipated to range from 0.139 to 0.213 . However, due to the underestimation of Trp content of the feed ingredients, the analysed dietary SID Trp:Lys ranged from 0.178 to 0.236 . Burgoon et al. (1992) reported an optimal total Trp requirement of $1.9 \mathrm{~g}$ - $\mathrm{kg}^{-1}$ for 6 to $16 \mathrm{~kg}$ pigs, which was equivalent to 0.138 SID Trp:Lys). However, Guzik et al. (2002) reported an optimal SID Trp requirement of $1.8 \mathrm{~g}$. $\mathrm{kg}^{-1}$ for 10 to $16 \mathrm{~kg}$ pigs, which was equivalent to 0.178 SID Trp:Lys. Similarly, Susenbeth and Lucanus (2005) did not observe any effect of dietary SID Trp on growth performance of 15 to $25 \mathrm{~kg}$ pigs. In their study, they had tested 6 levels of SID Trp:Lys, which ranged from 0.175 to 0.245 , indicating that the optimal SID Trp:Lys was less than or equal to 0.175 . Thus, in the Experiment 2 of the current study, the lower dietary SID Trp could have been equal to or greater than the optimal requirement. However, Jansman et al. (2010) reported an optimal SID Trp:Lys of 0.210 for nursery pigs. Also, Guzik et al. (2005) observed a linear increase in ADG of 7 to $16 \mathrm{~kg}$ nursery pigs when dietary SID Trp:Lys was increased from 0.145 to 0.195 , indicating an optimal dietary SID Trp:Lys was equal to or greater than 0.195 . Therefore, the optimal dietary SID Trp:Lys for piglets is variable. The optimal dietary SID Trp:Lys is affected by dietary level of SID Lys. The dietary level of SID Lys varied among the fore-mentioned studies in which optimal dietary SID Trp:Lys for pigs was determined, and this could partly explain variability of the optimal dietary SID Trp:Lys for piglets. 


\section{Conclusions}

In conclusion, the optimal dietary standardized ileal digestible (SID) lysine (Lys) level for piglets used in the current study is $10.2 \mathrm{~g} \cdot \mathrm{kg}^{-1}$, which is close to the recommended value by NRC (1998; $\left.10.1 \mathrm{~g} \cdot \mathrm{kg}^{-1}\right)$, but not NRC $\left(2012 ; 12.3 \mathrm{~g} \cdot \mathrm{kg}^{-1}\right)$. There was no effect of increasing dietary SID tryptophan:lysine (Trp:Lys) on growth performance and plasma urea $\mathrm{N}$ (PUN) of piglets, implying that the basal diet used in the current study was not deficient in Trp. Based on the analysis of Trp in the diets, it was apparent that dietary SID Trp:Lys ranged from 0.178 to 0.236 . Thus, it is suggested that the optimal SID Trp:Lys for early-weaned pigs used in the current study was either equal to or less than 0.178 , which is lower than NRC (1998) recommended value of 0.180 . However, it is difficult to tell whether or not the optimal SID Trp:Lys for early-weaned pigs used in the current study was similar to the NRC (2012) recommended value of 0.163 because the SID Trp:Lys values in the diets fed in current study were above 0.163 .

\section{Acknowledgements}

Presented in part at the Canadian Society for Animal Science Meeting at the University of Guelph, Guelph, Ontario, Canada, August 11-14, 2008.

\section{References}

AOAC, 2006. Association of Official Analytical Chemists, Official Methods of Analysis. $18^{\text {th }}$ Edition. Washington, DC

Boisen S., Hvelplund T., Weisbjerg M.R., 2000. Ideal amino acid profiles as a basis for feed protein evaluation. Livest. Prod. Sci. 64, 239-251

Burgoon K.G., Knabe D.A., Gregg E.J., 1992. Digestible tryptophan requirements of starting, growing, and finishing pigs. J. Anim. Sci. 70, 2493-2500

Canadian Council on Animal Care (CCAC), 2009. Guidelines on: the Care and Use of Farm Animals in Research, Teaching and Testing. Canadian Council on Animal Care. Ottawa, ON (Canada)

Coma J., Carrion D., Zimmerman D.R., 1995. Use of plasma urea nitrogen as a rapid response criterion to determine the lysine requirements of pigs. J. Anim. Sci. 73, 472-481

Commission Directive, 1998. Establishing Community Methods for the Determination of Amino-Acids, Crude Oils and Fats, and Olanquindox in Feeding Stuff and Amending Directive 71/393/EEC, Annex Part A: Determination of Amino Acids. Off. J. Eur. Comm. L257: 14-23

Commission Directive, 2000. Establishing Community Methods for the Determination of Vitamin A, Vitamin E and Trp, Annex Part C: Determination of Tryptophan. Off. J. Eur. Comm. L174: 45-50

Cromwell G.L., Calvert C.C., Cline T.R. et al., 1999. Variability among sources and laboratories in nutrient analyses of corn and soybean meal. J. Anim. Sci. 77, 3262-3273
Dean D.W., Southern L.L., Kerr B.J., Bidner T.D., 2007. The lysine and total sulfur amino acid requirements of six- to twelve-kilogram pigs. Prof. Anim. Sci. 23, 527-535

Eder K., Peganova S., Kluge H., 2001. Studies on the tryptophan requirement of piglets. Arch. Anim. Nutr. 55, 281-297

Fontaine J., Hörr J., Schirmer B.J., 2002. Near-infrared reflectance spectroscopy (NIRS) enables the fast and accurate prediction of essential amino acid contents. 2. Results for wheat, barley, corn, triticale, wheat bran/middlings, rice bran, and sorghum. J. Agric. Food Chem. 50, 3902-3011

Fontaine J., Hörr J., Schirmer B.J., 2004. Amino acid contents in raw materials can be precisely analyzed in a global network of near-infrared spectrometers: Collaborative trials prove the positive effects of instrument standardization and repeatability files. J. Agr. Food Chem. 52, 701-708

Guzik A.C., Pettitt M.J., Beltranena E., Southern L.L., Kerr J., 2005. Threonine and tryptophan ratios fed to nursery pigs. J. Anim. Physiol. Anim. Nutr. 89, 297-302

Guzik A.C., Southern L.L., Bidner T.D., Kerr B.J., 2002. The tryptophan requirement of nursery pigs. J. Anim. Sci. 80, 2646-2655

Jansman A.J.M., van Diepen J.Th.M., Melchior D., 2010. The effect of diet composition on tryptophan requirement of young piglets. J. Anim. Sci. 88, 1017-1027

Kendall D.C., Gaines A.M., Allee G.L., Usry J.L., 2008. Commercial validation of the true ileal digestible lysine requirement for eleven- to twenty-seven-kilogram pigs. J. Anim. Sci. 86, 324-332

Nam D.S., Aherne F.X., 1994. The effects of lysine:energy ratio on the performance of weanling pigs. J. Anim. Sci. 72, 1247-1256

NRC, 1998. Nutrient Requirements of Swine. $10^{\text {th }}$ Edition. National Research Council, National Academic Press. Washington, DC

NRC, 2012. Nutrient Requirements of Swine. $11^{\text {th }}$ Edition. National Research Council, National Academic Press. Washington, DC

Rademacher M., Sauer W.C., Jansman A.J.M., 2000. Standardized ileal digestibility of amino acids in pigs. The New System. Degussa-Hüls (Germany)

Robbins K.R., Saxton A.M., Southern L.L., 2006. Estimation of nutrient requirements using broken-line regression analysis. J. Anim. Sci. 84, E. Suppl. 13, E155-E165

Sato H., Seino T., Kobayashi T., Murai A., Yugari Y., 1984. Determination of the tryptophan content of feed and feedstuffs by ion-exchange liquid chromatography. Agr. Biol. Chem. 48, 2961-2969

Smith J.W., Tokach M.D., Nelssen J.L., Goodband R.D., 1999. Effects of lysine:calorie ratio on growth performance of 10 - to 25 -kilogram pigs. J. Anim. Sci. 77, 3000-3006

Susenbeth A., Lucanus U., 2005. The effect of tryptophan supplementation of diets of restricted- and unrestricted-fed young pigs. J. Anim. Physiol. Anim. Nutr. 89, 331-336

Van Cauwenberghe S., Relandeau C., 2000. L-tryptophan supplementation to enhance piglet growth. Ajinomoto Eurolysine Information No. 23, pp. 1-11

Wu J.G., Shi C., Zhang X., 2002. Estimating the amino acid composition in milled rice by near-infrared reflectance spectroscopy. Field Crop. Res. 75, 1-7

Yi G.F., Gaines A.M., Ratliff B.W., Srichana P., Allee G.L., Perryman K.R., Knight C.D., 2006. Estimation of the true ileal digestible lysine and sulfur amino acid requirement and comparison of the bioefficacy of 2-hydroxy-4-(methylthio)butanoic acid and DL-methionine in eleven- to twenty-six-kilogram nursery pigs J. Anim. Sci. 84, 1709-1721 